ББК 63.4

$$
\begin{gathered}
\text { Организация конференции и издание материалов проведены } \\
\text { при финансовой поддержке Российского фонда фундаментальных исследований, } \\
\text { проект № 19-09-20008 }
\end{gathered}
$$

Утверждено к печати Ученым советом ИИМК РАН

Редакционная коллегия тома II: А. В. Поляков, Е. С. Ткач (отв. редакторы), М. Т. Кашуба, Л. Б. Кирчо, Е. А. Черлёнок, В. Я. Стёганцева, А. И. Климушина

Рещензенты: д. и. н. Л. Б. Вишняцкий, д. и. н. А. А. Выборнов

Программный комитет конференции: академик РАН, д. и. н., проф. М. Б. Пиотровский (Государственный Эрмитаж, почетный председатель); д. и. н. В. А. Лапшин (ИИМК РАН, председатель); д. и. н. А. В. Головнёв (МАЭ РАН, сопредседатель); д. и. н. В. А. Дергачёв (Высшая антропологическая школа, Молдова, сопредседатель); д. и. н. И. Ф. Попова (ИВР РАН, сопредседатель); академик АН Республики Узбекистан, д. и. н., проф. Э. В. Ртвеладзе (сопредседатель); к. и. н. А. В. Поляков (ИИМК РАН, зам. председателя); к. и. н. В. А. Алёкшин (ИИМК РАН, зам. председателя); д. и. н. Ю. Е. Берёзкин (МАЭ РАН); Dr., Prof. Н. Бороффка

(Германский археологический институт, Германия); В. С. Бочкарёв (ИИМК РАН);

Dr. Э. Кайзер (Свободный университет Берлина, Германия); к. и. н. М. Т. Кашуба (ИИМК РАН); д. и. н. Л. Б. Кирчо (ИИМК РАН); к. и. н. А. В. Кияшко (Южный федеральный университет); к. и. н. П. Ф. Кузнецов (СГСПУ); к. и. н. Н. М. Малов (СНИГУ); к. и. н. В. П. Никоноров (ИИМК РАН); Ю. Ю. Пиотровский (Государственный Эрмитаж); д. и. н., проф. Д. Г. Савинов (Институт истории СПбГУ); к. и. н. В. Н. Седых (Институт истории СПбГУ); к. и. н. Н. Н. Скакун (ИИМК РАН); к. и. н. Н. Ф. Соловьёва (ИИМК РАН); к. и. н. А. И. Торгоев (Государственный Эрмитаж); к. и. н. Е. А. Черлёнок (Институт истории СПбГУ)

Организационный комитет конференции: к. и. н. А. В. Поляков (ИИМК РАН, председатель); к. и. н. В. А. Алёкшин (ИИМК РАН, зам. председателя); В. С. Бочкарёв (ИИМК РАН); к. и. н. М. Т. Кашуба (ИИМК РАН); д. и. н. Л. Б. Кирчо (ИИМК РАН);

А. И. Климушина (ИИМК РАН, отв. секретарь); к. и. н. В. П. Никоноров (ИИМК РАН); Ю. Ю. Пиотровский (Государственный Эрмитаж); В. Я. Стеганцева (ИИМК РАН); В. В. Терёхина (ИИМК РАН, МАЭ РАН, отв. секретарь); к. и. н. Е. С. Ткач (ИИМК РАН); И. Ж. Тутаева (Государственный Эрмитаж); к. и. н. Е. А. Черлёнок (Институт истории СПбГУ)

Древности Восточной Европы, Центральной Азии и Южной Сибири в контексте связей и взаимодействий в евразийском культурном пространстве (новые данные и концепции): Материалы Международной конференции, 18-22 ноября 2019 г., Санкт-Петербург. Т. ІІ. Связи, контакты и взаимодействия древних культур Северной Евразии и цивилизаций Востока в эпоху палеометалла (IV-I тыс. до н. э.). К 80-летию со дня рождения выдающегося археолога В. С. Бочкарёва. - СПб.: ИИМК РАН, Невская Типография, 2019. - 287 с.

ISBN 978-5-907053-35-9

DOI 10.31600/978-5-907053-35-9 
Тишкин А. А. 2019а. Бийкенская культура // Тишкин А. А. (ред.). История Алтая. В 3 т. Т. 1: Древнейшая эпоха, древность и средневековье. Барнаул; Белгород. С. 186-201.

Тишкин А. А. 20196. Майэмирская (майемерская) культура // Там же. С. 201-210.

Тишкин А. А., Леонова И. Ю. 2005. Погребальная практика носителей бийкенской культуры Алтая: семантика археологического комплекса // Евглевский А. В. (гл. ред). Структурно-семиотические исследования в археологии. Донецк. Т. 2. С. 279-294.

Чугунов К. В., Парцингер Г., Наглер А. 2017. Царский курган скифского времени Аржан-2 в Туве. Новосибирск.

Шульга П. И. 2008. Снаряжение верховой лошади и воинские пояса на Алтае. Ч. І: Раннескифское время. Барнаул.

\section{THE ROLE AND SIGNIFICANCE OF HORSES IN THE ACTIVITIES OF THE NOMADIC SOCIETIES OF ALTAI AND ADJACENT TERRITORIES OF THE ARZHAN-MAYEMIR PERIOD}

Alexey A. Tishkin

Altai State University, Barnaul, Russia

Keywords: Altai and adjacent territories, Arzhan-Mayemir period, nomadic societies, horse, harness outfits, osteological materials.

Archaeological materials yielded by excavations in the Altai and adjoining it territories with sites of the Arzhan-Mayemir period (late $9^{\text {th }}-$ second and third quarters of the $6^{\text {th }}$ cent. BC) allow us to solve a complex of problems concerned with the role and significance of horses in the life of early nomads. Of special importance are the animal skeletal remains here found and items of horse harness. Paleogenetic investigations and expansive morphological studies of the available osteological collections are conducted jointly by specialists from different national and foreign institutions. Radiocarbon dating holds a special place in these researches. Along with the application of natural science methods, the detailed recording and interdisciplinary interpretation of the archaeological materials under study remain of great importance. This is reflected in the projects of building electronic databases and allows the researchers to continue reconstructions based, inter alia, on the semantics of the facts of finding horses at funerary installations of the Biyken culture. Analysis of all the data obtained will provide unbiased reconstructions of different aspects of the history of nomadic societies in Central Asia.

КОЖАНЫЕ СУМОЧКИ В І ТЫС. ДО Н. Э.

\section{С ТЕРРИТОРИИ САЯНО-АЛТАЙСКОГО НАГОРЬЯ}

\section{В. С. Бусова}

Всероссийский художественный научно-реставраиионный иентр им. акад. И. Э. Грабаря, Москва, Россия

DOI: 10.31600/978-5-907053-35-9-107-109

Ключевые слова: Саяно-Алтайское нагорье, Тува, курганы, скифское время, эпоха хунну, археологическая кожа, мешочки, амулетницы.

Кочевник - адаптивный человек и вынужден постоянно носить с собой различные предметы быта, чтобы быть готовым к тем или иным изменениям среды. К седлу не сразу придумали стремена, а на одежде не сразу появились карманы для небольших повседневных предметов. Сумки, кошельки и сумочки, которые выполняли эту функцию ранее, фиксируются археологически в погребальном обряде кочевников Саяно-Алтайского нагорья с начала I тыс. до н. э. Они не выходят из обращения с течением последующих трех тысячелетий, 


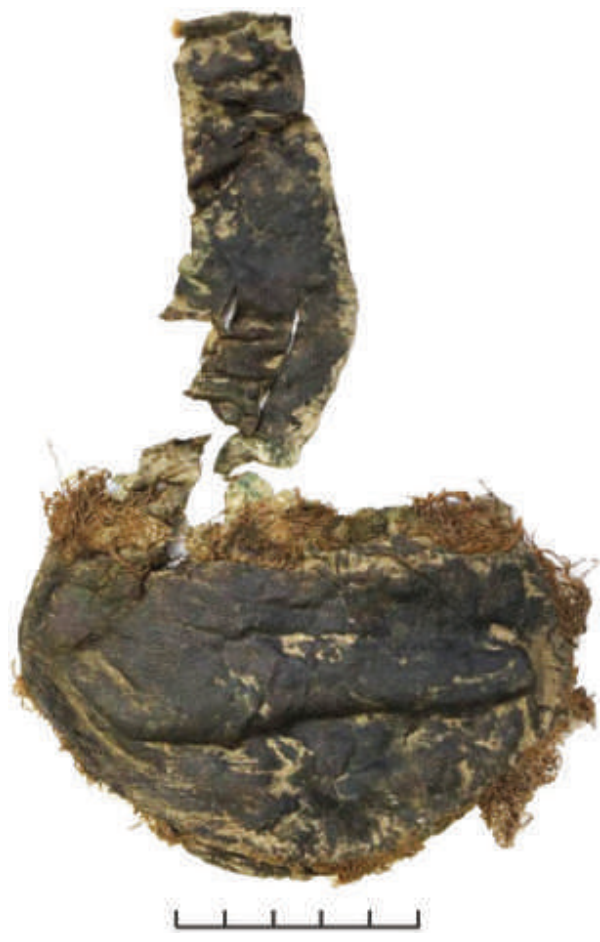

Рис. 1. Кожаная сумочка с гребешком внутри, могильника Аймырлыг VIII-53 даже тогда, когда в них остаётся не так много смысла в практическом плане. Безусловно, ношение кошелька или сумки близко связано с поясным комплексом и входит в набор символических кодов в культовом пространстве древних кочевников Саяно-Алтая. Отправной точкой для этого исследования стала работа с материалами IV-III вв. до н. э. из кург. 83 могильника Холаш (Семёнов 1997), где среди фрагментов ремней хорошо сохранился кожаный кошелек для деревянного наборного гребня (Бусова 2015). Ряд аналогий с предметами из кожи могильника Аймырлыг (Центральная Тува) и курганов пазырыкской культуры на Алтае позволяют выдвинуть предположение, что кожаные кошельки подобной конструкции довольно часто встречаются в погребениях.

Находки деревянных гребешков вместе с зеркалами из медных сплавов и сопровождающих их фрагментов войлочных и кожаных «чехлов» в женских погребениях двух возрастных категорий (18-25 л. и 45-55 л.) позволяют интерпретировать ношение подобного рода вместилищ как женский атрибут поясного набора (Жогова 2014: 136). Очень часто в могилах фиксируются остатки индивиду-

альных кожаных кошельков для наборов зеркал с шильями (изредка - с иглой). Сумочки, встречающиеся в памятниках VIII-III вв. до н. э. (например, Бай-Даг 8, Белое Озеро 4, Аймырлыг в Туве (рис. 1), и Уландрык, Пазырык 2 на Алтае), имеют две распространенные формы, определяемые содержимым: 1) «сердцевидная» форма с каплевидным низом, состоящая из основного отделения для гребешка и верхнего клапана, который мог быть использован, например, для хранения мотка сухожильных нитей; 2) либо сумочки в виде «мешочков», затягивающиеся шнурками или ремешками у основания горла. Первый тип сумочек встречается вместе с гребешками внутри и, вероятно, зеркалами. Ножи внутрь не помещали. Второй тип встречается в качестве так называемых сумочек-амулетниц. Внутрь их помещали срезанные волосы, зубы, ногти, сухие красящие пигменты или отдельно только иглы. Во II в. до н. э. на территорию Тувы приходят носители традиции хунну. При этом культура создания кожаных изделий радикальным образом не меняется, но появляются свои нюансы, едва заметные с первого взгляда. Меняется конструкция пояса, при сшивании изделий из кожи и меха используют и сухожильные нити, и шерстяные, притом, что ранее использовали только нити из сухожилий. Из двух типов кошельков дольше всех выживает форма «мешочка», размер которого варьирует в зависимости от содержимого. Например, на могильнике Терезин (II-I в. до н. э.) в кожаный мешочек-сумку размером около $20 \times 10$ см были помещены нож, фрагмент зеркала из медного сплава, веретено, пряслице и маленькая кожаная сумочка с неизвестным содержимым органического происхождения (погр. 27 - Килуновская и др. 2018).

В действительности, мы имеем совсем небольшое количество целых кожаных сумочек и кошельков, по которым можем судить с высокой долей вероятности о традициях и закономерностях кожевенного и скорняжного ремесел в I тыс. до н. э. Внимательное отношение к находкам изделий из органических материалов поможет взглянуть на них с новой стороны. 


\title{
Литература
}

Бусова В. С. 2015. Технологический анализ изделий из кожи скифского времени из могильника Холаш // VI International Academic Conference "Ancient Cultures of Mongolia, Baikalian of Siberia and the Northern Area of China" (12-16 October 2015, Huhhot). Huhhot. C. 1262-1269.

Жогова Н. А. 2014. Типология составных гребней эпохи ранних кочевников Саяно-Алтая // Археологические вести. № 20. СПб. С. 116-142.

Килуновская М. Е., Леус П. М., Бусова В. С. 2018. Уникальные наборы предметов из женских погребений эпохи хунну на могильнике Терезин (Центральная Тува) // Рафикова Я. В. (отв. ред.). Мужской и женский мир в отражении археологии: Материалы Всерос. с междунар. участием конф., г. Уфа (19-21 ноября 2018 г.). Уфа. С. 137-142.

Семёнов Вл. А. 1997. Монгун-Тайга. СПб.

\section{LEATHER PURSES OF THE $1^{\text {ST }}$ MILL. BC FROM THE SAYAN-ALTAI HIGHLANDS}

\section{Varvara S. Busova}

I. Grabar Art Conservation Center, Moscow, Russia

Keywords: Sayan-Altai highlands, Tuva, kurgans, Scythian period, Hunnu period, archaeological leather, purses, amulet cases.

These theses present studies of finds of leather objects from funerary sites of the $1^{\text {st }}$ mill. BC in the Sayan-Altai highlands. The finds include leather pouches, purses and cases for combs, mirrors, knives, awls (needles), etc. All the objects depicted are subdivided into two major types: "cordiform" and "pouch-shaped" ones. During the $8^{\text {th }}-3^{\text {rd }}$ centuries BC, in the territory of Tuva certain leatherworking traditions were preserved and only at the turn of the $2^{\text {nd }}$ cent. $\mathrm{BC}$ changes, possibly related to the Hunnu invasion, took place. Only one type continued in the new era - pouches of different size. The capacity of the latter was expanded, as well as their function.

\section{РАДИОУГЛЕРОДНОЕ ДАТИРОВАНИЕ КУРГАНОВ С ПРЕДМЕТАМИ КИТАЙСКОГО ИМПОРТА ИЗ МОГИЛЬНИКА СКИФСКОЙ ЭПОХИ ЧИНЕТА-ІІ (СЕВЕРО-ЗАПАДНЫЙ АЛТАЙ) ${ }^{1}$}

\author{
П. К. Дашковский \\ Алтайский государственный университет, Барнаул, Россия
}

DOI: 10.31600/978-5-907053-35-9-109-111

Ключевые слова: Алтай, пазырыкская культура китайский импорт, радиоуглеродное датирование, хронология.

Могильник Чинета-II входит в состав Чинетинского археологического микрорайона, расположенного на левом берегу р. Иня в 1,0-1,4 км к ЮЮВ от с. Чинета Краснощековского р-на Алтайского края (Северо-Западный Алтай). Особого внимания заслуживают курганы пазырыкской культуры № 21 и 31, в которых были обнаружены предметы китайского импорта. Результаты раскопок курганов частично опубликованы, поэтому отметим только несколько наиболее важных моментов для установления их датировки. Среди предметов сопроводительного инвентаря особого внимания заслуживает золотая серьга

\footnotetext{
${ }^{1}$ Работа подготовлена при финансовой поддержке РФФИ, проект № 19-49-220002, «Памятники Чинетинского археологического микрорайона на Алтае: культурно-историческая интерпретация артефактов и возможности использования полученных результатов в туристическом кластере региона».
} 